\title{
PHYSICAL AND MECHANICAL PROPERTIES OF MULTI-ELEMENT COATINGS
}

Zharmagambetova G. A., Kudusova I. A., Laurinas V. Ch. Academician E.A. Buketov Karaganda University

A number of experiments were conducted to measure the physical and mechanical properties of multi-element coatings. To apply $\mathrm{CrNiTiFeCu}$ coatings on a nickel-chromium substrate, the technology of magnetron deposition in an atmosphere of argon or nitrogen was used.

The results of measurements of the microhardness as well as the coefficients of friction and wear resistance of the applied CrNiTiFeCu thin films are presented.

The findings indicate that the studied samples show a high microhardness and wear resistance. Consequently, there is a possibility to extend the lifespan of mechanisms and machines parts.

Keywords: multi-element coating, protective coating, coefficient of friction, microhardness, wear.

Introduction. The important factor nowadays is the increase in the service characteristics of machines parts due to improved wear resistance. There should be noted that it is impossible to obtain multi-element coatings, which can be very promising protective coatings of parts, using classical metallurgy. However, it can be implemented using physical vapor deposition methods. The properties of these alloys in operation depend not only on the chemical composition, but also on a number of parameters, the variation of which when applying multi-element coatings allows these properties to change in a wide range.

Experiment. Disks with $12 \mathrm{~mm}$ diameter and $3 \mathrm{~mm}$ thickness were used to obtain multi-element coatings. The disks were compressed from micro-powders of 5 elements $\mathrm{Cr}, \mathrm{Ni}, \mathrm{Ti}, \mathrm{Fe}, \mathrm{Cu}$, pre-mixed in a ball mill. After pressing, the disks were sintered in a vacuum furnace SGV 2.4-2/15-I3.

In the vacuum ion-plasma coating application plant NNV-6.6-I1, thin ( $\sim 5$ microns $)$ CrNiTiFeCu films were deposited by magnetron deposition in an assisting gas atmosphere (argon or nitrogen) on substrates with $5 \mathrm{~mm}$ thickness and a polished surface area $(2 \mathrm{sq} . \mathrm{cm})$, which is made of a nickel-chromium alloy.

Figures 1 and 2 show the spectra taken with the MIRA-3 LMU reflection electron microscope from samples which were coated in a nitrogen atmosphere (Fig.1) and the argon atmosphere (Fig. 2).

Next, the friction coefficients of the applied coatings were measured, because this value has an important impact on the technical efficiency and durability of industrial products [1]. The friction measurements were carried out for each sample 20 times per friction surface type. Friction surface based on copper, steel, and aluminum were used.

To measure the coefficient of friction, an experimental plant "Informacionno-izmeritel'noe ustroistvo dlya opredeleniya koefficienta treniya skol'zheniya"(Information and measuring device for determining the coefficient of sliding friction) was used, which was developed and created by employees of the SIC "Ion-Plasma Technologies and Modern Instrument Engineering" (KarU). Fig. 3 shows how it looks.

The results are shown in Table 1.

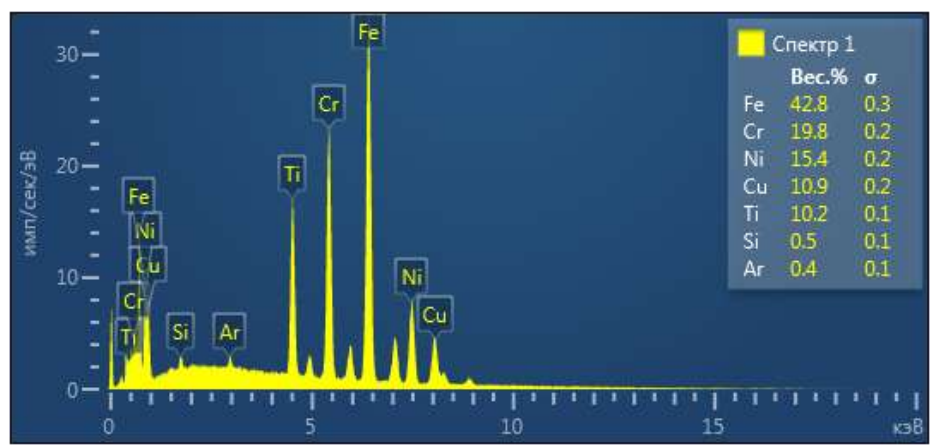

Figure 1 Spectrum of CrNiTiFeCu coating applied in a nitrogen atmosphere 


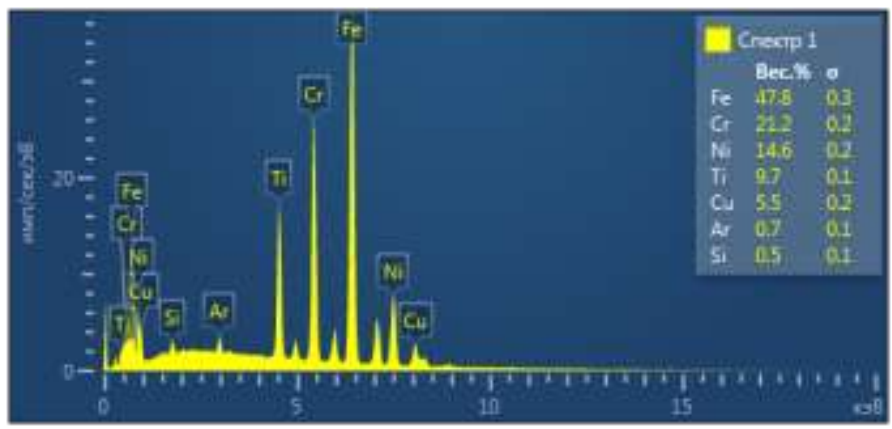

Figure 2 Spectrum of CrNiTiFeCu coating applied in an argon atmosphere

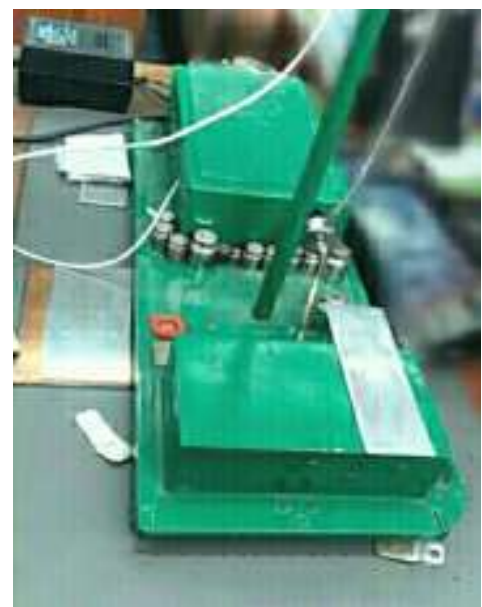

Fig. 3 Information-measuring device for determining the coefficient of sliding friction

The microhardness of the coatings was measured using the Vickers hardness testing machine HVS-1000A [2]. The accuracy of the indentation depth measurement was \pm 0.04 microns. One sample has been measured 20 times. The results are shown in Table 1.

\begin{tabular}{|c|c|c|c|c|c|}
\hline \multirow{2}{*}{ An object } & \multicolumn{3}{|c|}{ Coefficient of friction } & \multirow{2}{*}{ Microhardness HV } & \multirow{2}{*}{ Wear, mcg/s } \\
\cline { 2 - 4 } & by Al & by steel & by Cu & 1153 & 0.08 \\
\hline $\begin{array}{c}\text { CrNiTiFeCu coating } \\
\text { (in a nitrogen environment) }\end{array}$ & 0.06 & 0.06 & 0.05 & 790 & 0.1 \\
\hline $\begin{array}{c}\text { CrNiTiFeCu coating } \\
\text { (in the argon environment) }\end{array}$ & 0.07 & 0.06 & 0.08 & 183 & 0.37 \\
\hline Substrate & 0.1 & 0.25 & 0.39 & 183 \\
\hline
\end{tabular}

The determination of the wear of the applied coatings [3,4] was measured on a tribometer, also created by employees of the SIC "Ion-Plasma Technologies and Modern Instrument Engineering" (KarU).

When ball, which is made of high-hardness steel, rotates, contacting with the coating, the mentioned coating wears out. Then, a spherical hole is formed in the thin layer of coating applied to the substrate. The number of holes (20) and the one point contact time ( 25 minutes) on one sample were selected in such a way that the accuracy (10 micrograms) of the RADWAG AS 60/220.R2 analytical balance was sufficient to obtain reliable information about the the sample mass loss, while the depth of the hole did not exceed the thickness of the coating layer -5 microns.

In addition, similar measurements were carried out with substrates, the results of the measured coefficients of friction, microhardness and wear of the nickel-chromium alloy are also shown in Table 1

Conclusion. The results indicate that this multi-element coating has a high hardness, especially when applied in a nitrogen atmosphere, which, with a very small coefficient of friction, significantly increases wear resistance.

There should be noted that the coating applied in argon, significantly inferior to the coating applied in nitrogen, with a hardness of almost one and a half times and is not much inferior to it in terms of wear resistance.

Therefore, the application of $\mathrm{CrNiTiFeCu}$ coating with a thickness of 5 microns will increase the lifespan of machine and mechanisms parts. 
1. Cha S. (eds.) Energy Consumption Due to Friction in Motored Vehicles and Low-Friction Coatings to Reduce It. -Springer International Publishing Switzerland: Coating Technology for Vehicle Applications, 2015. - 248p.

2. Holmberg K., Erdemir A. Influence of tribology on global energy consumption, costs and emissions. -VTT Technical Research Centre of Finland, 2017. -360p.

3. Urbahs A. (eds.) Evaluation of the Physical and Mechanical Characteristics of Ion-Plasma Antifriction Coatings Based on Ti-Cu. -Trans Tech Publications Ltd, Switzerland: Key Engineering Materials Submitted, 2018. -366p.

4. Shubin A. Comparative physical-tribological properties of anti-friction ion-plasma Ti-C-Mo-S coating on VT6 alloy or 20X13 and 40X steels. XII International Conference Radiation-thermal Effects and Processes in Inorganic Materials: Publishing IOP Conf. Series: Materials Science and Engineering 168, 2017. - 012038. 